This is an Accepted Manuscript of an article published by Taylor \& Francis in Environmental Education Research on 13/05/2020, available online:

https://www.tandfonline.com/doi/full/10.1080/13504622.2020.1764505 


\title{
Understanding policymakers' perspectives on evidence use as a mechanism for improving research-policy relationships
}

\author{
Louise Shaxson \& Annette Boaz \\ Kingston University, Centre for Health Care and Social Research \\ Faculty of Health, Social Care and Education \\ Hunter Wing, $6^{\text {th }}$ Floor, Cranmer Terrace \\ London, UK SW17 0RE
}

\begin{abstract}
This Special Issue examines how relationships between research and policy in environmental and sustainability education (ESE) can be strengthened. Our contribution draws on three cases from outside the ESE space to analyse policymakers' perspectives on using evidence to inform decision-making, and to show that government-based policymakers develop 'policy narratives' which influence their evidence use. We also illustrate how government departmental systems and processes lead policymakers to develop 'evidence narratives' which help them make sense of what evidence to use and how to use it in the policy development process. At its core, such work involves negotiating three normative positions around evidence, concerning: fidelity to science, democratic representation, and cost-effective use of public money. In light of this, we suggest that where policy narratives and evidence narratives interact should be interpreted as a key site for empirically investigating evidence-informed policymaking activities. Developing a detailed awareness of what policymakers do on a daily basis, and discerning how organisational systems and processes influence particular demands for evidence and how it is used, will foster a better understanding of the relationships between research and policy.
\end{abstract}

\section{Introduction}

In 2018, a review of international trends, priorities and challenges in Environmental and Sustainability Education examined ongoing debates about how to link research to policy in the field of environmental and sustainability education (ESE). 
(van Poeck, Lysgaard, and Reid 2018). The authors noted that ESE researchers mainly acted either as independent expert advisers to policymakers, or as solvers of discrete environmental sustainability problems. In their opinion, separating these two functions risks reinforcing a demarcation between the science and politics of environmental and sustainability education, which would be unhelpful for such a sensitive and contentious field. This current Special Issue builds on these concerns to ask how research-policy relationships in ESE can be made more productive by ensuring that ESE research can be better informed by an understanding of ESE policy and vice versa.

Van Poeck, Lysgaard and Reid echoed Læssøe et al's (2013) call to improve the 'documentary role' of policy research for ESE; uncovering and recording what happens during the policymaking process to explore the detail of its complex, contested and social nature (Læssøe, Feinstein, and Blum 2013; Aikens, McKenzie, and Vaughter 2016). The argument for examining the details of ESE policy processes echoes calls from outside the ESE space to improve our understanding of how research and policy can be linked, by focusing on policymakers' perspectives on evidence use (Oliver, Lorenc, and Innvær 2014). In this article we briefly review three studies from outside the ESE field — health policy, education policy and public management — that use a documentary approach to investigate these perspectives. Together, they suggest that investigating how policymakers develop 'policy narratives' and 'evidence narratives' and how these narratives interact with each other-could offer researchers a new approach for exploring how evidence is used in public policymaking for ESE and how this shapes the demand for ESE research.

\section{Studying the relationship between evidence and policy}

There is a broad literature on evidence-informed decision-making in government, reflecting a long-standing interest in the relationships between academic 
research, public policymaking and professional practice (Nutley, Walter, and Davies 2007; Head 2008). Much of the literature stems from two concerns. The first is to use evidence to challenge or critique existing or planned policies (Cairney 2018). The second is to improve the role of robust evidence in policy and practice decisions to improve good governance in public policymaking (Stone 2002; Parkhurst 2017). As with the literature on ESE, these concerns are linked to debates about how researchers can engage effectively with research users to improve the relevance and quality of research, to enhance its impact and to connect with other processes of knowledge generation (Rickinson, Sebba, and Edwards 2011; Gagliardi et al. 2016). Researchers have studied the mechanics of how evidence is used to inform policy decisions and how it is translated, exchanged and brokered between evidence producers and evidence users (Oliver, Lorenc, and Innvær 2014; Ward 2016). Different schools of thought such as evaluation (Weiss 1979), science and technology studies (Jasanoff 2005), policy studies (Cairney 2018) and implementation science (Nilsen 2015)—while unconnected to each other-have brought nuance to these debates.

The idea that policymaking is a series of bounded rational decisions (Botterill and Hindmoor 2012) is critiqued by authors such as Cairney (Cairney 2018) who emphasise the political, negotiated nature of policy processes and the need to formulate arguments and take decisions based on limited, uncertain and ambiguous evidence (Cairney, Oliver, and Wellstead 2016). Many of these arguments will be familiar to ESE researchers. But while there are many explorations of how evidence is negotiated and used in specific policy areas, these have tended to be for the purpose of critiquing the ways decisions have ultimately been made. There has to date been little documentation of what policymakers actually do on a day-to-day basis and how their daily 'work practices' (Schatzki, Knorr Cetina, and von Savigny 2001) influence how 
they use evidence (Oliver, Lorenc, and Innvær 2014). Without this empirical understanding, researchers will be challenged to analyse policymakers' perspectives on evidence use and to help civil servants develop more effective practices (Hallsworth, Parker, and Rutter 2011).

To gain this understanding we identified three recent studies which gathered detailed information about the interactions between evidence and policymaking in three different geographies and policy areas. In the UK, Maybin (Maybin 2016) conducted in-depth interviews with policymakers from the Department of Health between 2009 and 2011, analysing documents and observing a range of meetings at which aspects of health policy were discussed. She investigated how mid-ranking civil servants used evidence to get up to speed on new issues, drill into the detail of a topic or conceptualise policy challenges in order to make decisions themselves or to recommend the decisions that others should take. In Australia Rickinson et al. (Rickinson et al. 2017, 2018) used document analysis, interviews and observational work to examine how educational policymakers used evidence in the policy development process. The research focused on three policy initiatives within the Department of Education and Training. It explored what types of evidence were used, who was involved in the process, what drove and hindered the effective use of evidence, and what could be done to improve it. Shaxson (Shaxson 2019) used document analysis to examine the systems and processes put in place by a range of departments in the UK and USA to support evidence use in policy development. Referring to Parkhurst's principles of the good governance of evidence (Parkhurst 2017) the research analysed whether, in aggregate, these practices contributed to a holistic approach to evidence-informed policymaking.

The three studies examine how policymakers find and use evidence from different perspectives. Analysing all three together highlights two broad findings of 
interest to ESE researchers. These are described in more detail in the next two sections. The first is that as policymakers work with their colleagues to inform decision making processes, they develop 'policy narratives' which influence — and are influenced bytheir own perspectives on evidence. The second is that department-wide systems and processes help policymakers negotiate different normative positions around evidence. We suggest that this results in the creation of 'evidence narratives' which similarly influence their perspectives on how evidence could and should be used.

\section{Policymakers use evidence to shape policy narratives}

Policymakers' daily work practices (Schatzki, Knorr Cetina, and von Savigny 2001) include developing documents, overseeing ongoing programmes of work, advising ministers, responding to ad-hoc enquiries including questions in Parliament and supporting the work of expert committees (Maybin 2016). These practices help define what the problem is, keep issues on the agenda, identify drivers of change, challenge assumptions and design and select interventions (Rickinson et al. 2017). In doing this, policymakers must negotiate different problem frames, interests and perspectives on key issues (Head 2016). They use a range of techniques to do thismaking complex phenomena more manageable by visualising, conceptualising, defining and categorising what policies aim to do and who they aim to benefit. They also develop and test out ideas and proposals on colleagues and external advisers; using evidence tactically to persuade others of the ideas' validity, to mobilise support or to provide an independent voice in order to defuse conflicts over policy proposals (Maybin, ibid).

Maybin and Rickinson et al found that the aim of policymakers' practices is not to define what is correct but to build, test and communicate a coherent policy 'narrative': a storyline that helps people make sense of, organise and transmit 
information about the past, present and possible future of a policy issue (see also Wilkinson 2011). Such narratives shape the decisions that are subsequently taken: a critical consideration for Maybin's health policymakers was to create narratives that could be defended against internal and external critiques including from colleagues in other departments, stakeholder groups, Parliament and the media. But policy narratives and the ideas they contain are malleable (Smith 2014) as policymakers seek to keep key issues on the table while simultaneously responding to critiques and attempting to align these narratives with other policy agendas. How effective policymakers are at this process of alignment depends on their 'policy know-how' (Maybin 2016, 136): the technical, organisational and networking skills they need to do their jobs effectively and the rules, procedures and historical context from which each issue has arisen (Howlett and Wellstead 2011).

Different types of evidence are used to inform the detail of policy narratives. Maybin and Rickinson et al. note the use of evidence from programme evaluations, internal and external stakeholder consultations, data from state, national and international assessments, meetings with frontline staff, reports from consultants and advisors and evidence from researchers who are considered by policymakers to be particularly authoritative. These different types of evidence would be combined to shape the narrative, test ideas and challenge the internal coherence of emerging proposals. Rickinson et al. found that the range of evidence sources used by education policymakers was wider during the policy development phase than in subsequent phases where policymakers placed more emphasis on testing and communicating the narrative with stakeholders. This observation supports Maybin's finding that when policymakers began to communicate with key stakeholders to negotiate their buy-in to a particular 
policy proposal, having robust evidence became less important than having a coherent narrative.

\section{Department-wide systems and processes also influence how evidence is used}

Most government departments have broad remits and will be developing policy narratives for many different issues simultaneously. While policymakers have latitude to develop their own relationships around evidence, researchers working on public sector reform agree that changing organisational practices such as processes and structures can help improve government effectiveness (Pollitt 2013). In the third study analysed here, Shaxson (2019) reviewed how various practices to strengthen the use of evidence developed in several government departments in the UK and USA. Seven practices were identified: senior officials with mandates to oversee the use of evidence, independent expert advisory committees, quality frameworks, strategy documents that took a forward look at what evidence was likely to be needed in future, working groups, analytical toolboxes, and guidelines and standards for evidence quality. As well as contributing evidence to developing individual policy narratives, policy officials also supported department-wide activities such as risk planning, effective budget management, and stimulating innovation.

The seven practices serve different purposes: advising political representatives, strengthening decision-making, demonstrating achievement of outcomes, managing budgets effectively, building partnerships, raising evidence quality, and maintaining and developing capacity and capability for evidence use. A single practice may serve multiple purposes: for example, a senior official may be simultaneously responsible for using evidence to advise politicians, managing human and financial resources and demonstrating how well departmental goals are being achieved. Other policymakers could be working to understand whether outcomes are being delivered effectively, using 
quality frameworks to help them decide which sources of evidence could be considered robust in different implementing contexts.

There are two main findings. First, there appears to be broad agreement within the departments studied by Shaxson (2019) on the need for formal structures and processes to support the use of evidence inside government departments. However, there is considerable variability in what those structures and processes look like and how extensively they cover the different aspects of evidence use. Second, the analysis highlighted three normative positions around evidence that need to be constantly negotiated: fidelity to science (ensuring high quality evidence), democratic representation (recognising that policymaking is both a political and a technical endeavour) and effective management of public resources. Policymakers' perspectives on evidence use may therefore develop somewhat separately from policy narratives. They are influenced by how the three normative positions on evidence are negotiated and how those negotiation processes are mediated by each department's structures and processes.

Drawing together these three studies leads us to suggest a new concept that could encapsulate the results of these mediated negotiations. Just as policy narratives help policymakers make sense of, organise and transmit information about the policy issue, we propose that policymakers may simultaneously be developing 'evidence narratives' to help them make sense of, organise and transmit information about what evidence they are using to inform decision-making and why. We suggest that one interpretation of evidence-informed policymaking could be as the site of interaction between evidence narratives and policy narratives. 


\section{Understanding policymakers' perspectives on evidence use: suggestions for ESE research}

In the call for proposals for this Special Issue, the editors quote the appeal from Lingard (2013, p 113) to 'reconsider...the actual and desired nature of research-policy relationships in education'. Lessons from outside the ESE space suggest that one fruitful avenue for enquiry is to analyse policymakers' perspectives on evidence use by developing an empirical understanding of what policymakers do on a daily basis; how policy narratives develop and the organisational systems and processes that shape how evidence is used in the policy process. Doing this would help ESE researchers understand how policymakers' demands for evidence are shaped and what this implies for how researchers (and other providers of evidence) can engage more productively with policymakers.

The three studies referenced in this article cover different policy environments (Australia, the UK and the USA) and policy areas (health, environment and education); suggesting that their findings may be more widely applicable. But the proposed concept of an 'evidence narrative' needs further examination: how do policymakers negotiate the three normative positions around evidence? How do organisational systems shape these negotiation processes? Where and how do evidence narratives interact with policy narratives and to what effect? What does this imply for the roles ESE researchers could play in strengthening research-policy relationships?

Working in this documentary role, in detail and in situ, could also help ESE researchers address another of van Poeck, Lysgaard and Reid's concerns: to reduce the demarcation between the science and the politics of environmental sustainability education. Any insights gained in this way would not be limited to ESE research alone. By helping us understand how policymakers' perspectives on evidence use develop, 
ESE researchers could also make a significant contribution to the wider literature on evidence-informed policymaking. 


\section{References}

Aikens, K, M McKenzie, and P Vaughter. 2016. "Environmental and Sustainability Education Policy Research: A Systematic Review of Methodological and Thematic Trends." Environmental Education Research 22 (3):333-59. https://doi.org/10.1080/13504622.2015.1135418.

Botterill, L, and A Hindmoor. 2012. "Turtles All the Way down: Bounded Rationality in an Evidence-Based Age." Policy Studies 33 (5):367-79. https://doi.org/10.1080/01442872.2011.626315.

Cairney, P. 2018. “The UK Government's Imaginative Use of Evidence to Make Policy.” British Politics. https://doi.org/10.1057/s41293-017-0068-2.

Cairney, P, K Oliver, and A Wellstead. 2016. "To Bridge the Divide between Evidence and Policy: Reduce Ambiguity as Much as Uncertainty." Public Administration Review 76 (3):399-402. https://doi.org/10.1111/puar.12555.

Gagliardi, A, W Berta, A Kothari, J Boyko, and R Urquhart. 2016. “Integrated Knowledge Translation ( IKT ) in Health Care : A Scoping Review." Implementation Science. Implementation Science, 1-12. https://doi.org/10.1186/s13012-016-0399-1.

Hallsworth, M, S Parker, and J Rutter. 2011. "Policy making in the real world." London: Institute for Government. https://www.instituteforgovernment.org.uk/sites/default/files/publications/Policy making in the real world.pdf.

Head, B. 2008. “Three Lenses of Evidence-Based Policy.” Australian Journal of Public Administration 67 (1):1-11. https://doi.org/10.1111/j.1467-8500.2007.00564.x.

_ 2016. “Toward More 'Evidence-Informed' Policy Making?” Public Administration Review 76 (3):472-84. https://doi.org/10.1111/puar.12475.

Howlett, M, and A Wellstead. 2011. "Policy Analysts in the Bureaucracy Revisited : The Nature of Professional Policy Work in Contemporary Government." Politics \& Policy 49 (4):613-33.

Jasanoff, S. 2005. Designs on Nature: Science and Democracy in Europe and the United States. Princeton University Press. 
Læssøe, J, N Weeth Feinstein, and N Blum. 2013. "Environmental Education Policy Research - Challenges and Ways Research Might Cope with Them." Environmental Education Research 19 (2):231-42. https://doi.org/10.1080/13504622.2013.778230.

Lingard, B. 2013. "The Impact of Research on Education Policy in an Era of EvidenceBased Policy." Critical Studies in Education 54 (2). Routledge:113-31. https://doi.org/10.1080/17508487.2013.781515.

Maybin, J. 2016. Producing Health Policy: Knowledge and Knowing in Government Policy Work. Basingstoke: Palgrave Macmillan.

Nilsen, P. 2015. "Making Sense of Implementation Theories, Models and Frameworks." Implementation Science 10 (1). BioMed Central:53. https://doi.org/10.1186/s13012-015-0242-0.

Nutley, S, I Walter, and H Davies. 2007. Using Evidence: How Research Can Inform Public Services. Bristol: Policy Press.

Oliver, K, T Lorenc, and S Innvær. 2014. "New Directions in Evidence-Based Policy Research: A Critical Analysis of the Literature." Health Research Policy and Systems 12 (34). BioMed Central. https://doi.org/10.1186/1478-4505-12-34.

Parkhurst, J. 2017. The Politics of Evidence: From Evidence-Based Policy to the Good Governance of Evidence. Taylor \& Francis. https://doi.org/doi:10.4324/9781315675008.

van Poeck, K, J Lysgaard, and A Reid. 2018. Environmental and Sustainability Education Policy: International Trends, Priorities and Challenges. London: Routledge/Taylor \& Francis. https://www.worldcat.org/title/environmental-andsustainability-education-policy-international-trends-priorities-andchallenges/oclc/991645018?referer=di\&ht=edition.

Pollitt, C. 2013. “The Evolving Narratives of Public Management Reform.” Public Management Review 15 (6):899-922. https://doi.org/10.1080/14719037.2012.725761.

Rickinson, M, K de Bruin, L Walsh, and M Hall. 2017. "What Can Evidence-Use in Practice Learn from Evidence-Use in Policy?” Educational Research 59 (2). Routledge:173-89. https://doi.org/10.1080/00131881.2017.1304306. 
Rickinson, M, J Sebba, and A Edwards. 2011. Improving Research through User Engagement. Abingdon: Routledge.

https://research.monash.edu/en/publications/improving-research-through-userengagement.

Rickinson, M, L Walsh, K de Bruin, and M Hall. 2018. "Understanding Evidence Use within Education Policy: A Policy Narrative Perspective." Evidence \& Policy: A Journal of Research, Debate and Practice x (x):1-18. https://doi.org/10.1332/174426418x15172393826277.

Schatzki, T, K Knorr Cetina, and E von Savigny. 2001. The Practice Turn in Contemporary Theory. London: Routledge. https://doi.org/0-203-97745-9.

Shaxson, L. 2019. "Uncovering the practices of evidence-informed policymaking." Public Money \& Management 39 (1):46-55. https://doi.org/ $10.1080 / 09540962.2019 .1537705$

Smith, K E. 2014. "The Politics of Ideas: The Complex Interplay of Health Inequalities Research and Policy." Science and Public Policy 41:561-74. https://doi.org/10.1093/scipol/sct085.

Stone, D. 2002. Policy Paradox: The Art of Political Decision-Making. 2nd revise. New York: W. W. Norton \& Company.

Ward, V. 2016. "Why, Whose, What and How? A Framework for Knowledge Mobilisers." Evidence \& Policy. https://doi.org/http://dx.doi.org/10.1332/174426416X14634763278725.

Weiss, C. 1979. “The Many Meanings of Research Utilization.” Public Administration Review 39 (5):426-31.

Wilkinson, K. 2011. “Organised Chaos: An Interpretive Approach to Evidence-Based Policy Making in Defra." Political Studies 59:959-77. https://doi.org/10.1111/j.1467-9248.2010.00866.x. 